\title{
Genetic Divergence and Cluster Analysis in Coriander Germplasm (Coriandrum sativum L.) in High Hills of Garhwal Himalayas
}

\author{
Jaidev Chauhan $^{1 *}$, Suyanka Raturi ${ }^{2}$, Ajaya Paliwal ${ }^{2}$ and Pankaj Bahuguna ${ }^{3}$
}

${ }^{I}$ Department of Herbal Biotechnology Division, High Altitude Plant Physiology Research Centre (HAPPRC), H.N.B.G.U. (A Central University), Srinagar Garhwal, Uttarakhand 246174, India

${ }^{2}$ Department of Genetics and Plant Breeding, ${ }^{3}$ Department of Statistics and Computer Application, University of Horticulture and Forestry, Bharsar, Pauri Garhwal, Uttarakhand 246123, India

*Corresponding author:

\begin{abstract}
A B S T R A C T
Twenty four genotypes of coriander were evaluated in Kharif season for different

Keywords

Coriander, Genetic diversity and Genetic divergence horticultural traits viz., days to $50 \%$ flowering, days to first umbel unfolding, Maturity duration, plant height, primary branches per plant, secondary branches per plant, test weight, fruits per umbel, fruits per umbellate, seed yield per plot and seed yield per plant etc. Cluster analysis based on Ward's minimum variance procedure distributed the into 5 clusters indicating their broad genetic base of which Maximum numbers of genotypes were accommodated in the cluster-IV (9) followed by cluster-I (4) cluster-II (4) and

Article Info

Accepted:

10 March 2019

Available Online:

10 April 2019 cluster-V (4). The intra cluster distance was found maximum in cluster III and minimum in cluster II. Whereas, highest inter cluster distance was recorded between cluster III and IV and lowest was observed between cluster IV and V. While there genetic diversities were classified on the basis of $\mathrm{D}^{2}$ analysis these genotypes were grouped into five divergent clusters and hybridization between cluster III and IV is expected to give maximum heterotic cross combinations in future breeding programs.
\end{abstract}

\section{Introduction}

Coriander (Coriandrum sativum L.) belongs to family Apiaceae originated from the Mediterranean region. Coriander is a popular seed spice which is grown from temperate to tropical regions of the world. It is one of the important seed spice. Coriander is useful as spice, in a form of curry powder, as in confectionary and in flavouring gin. Economic returns to seed spice growers are high due to more yields per unit area in short growing period. Genetic variability plays an important role in a crop in selecting the best genotypes for making rapid improvement in yield and other desirable characters as well as 
to select the potential parent of hybridization programs.

\section{Materials and Methods}

The investigation was carried out at the Medicinal and Aromatic Block, Department of Spices, Plantation, Medicinal and Aromatic Plants, College of Horticulture, Bharsar, VCSG Uttarakhand University of Horticulture and Forestry Bharsar. Seeds were sown directly in the field during the month of February 16, 2016 at a spacing of $(30 \times 15) \mathrm{cm}$ in a plot of $(1.5 \times 1.2) \mathrm{m}^{2}$ size. There were five rows in each plot. Forty plants of each genotype were planted in each replication. Each genotype was sown in a Random Complete Block Design (RCBD) with three replications. The standard cultural practices recommended in the Package of Practices for Seed Spices Crops, were followed to ensure a healthy crop stand. The obtained data was analyzed for genetic divergence.

\section{Results and Discussion}

\section{Genetic divergence studies}

In the present studies, the genetic divergence observed among twenty four diverse genotypes of Coriander showed good quantum of divergence (Fig. 1). All the genotypes were grouped into 5 clusters using the Ward's minimum variance procedure (Anderberg, 1993) and the distributions of the genotypes into different clusters are depicted in Table 1 and Figure 2. Maximum numbers of genotypes were accommodated in the cluster-IV (9) followed by cluster-I (4) cluster-II (4) and cluster-V (4). The average intra and inter-cluster Euclidean ${ }^{2}$ distance were estimated based on Ward's minimum variance and are presented in the Table 2. The intra cluster distance was found maximum in cluster III and minimum in cluster II. Whereas, highest inter cluster distance was recorded between cluster III and IV and lowest was observed between cluster IV and $\mathrm{V}$. The nearest and farthest cluster for each of the five clusters is presented in Table 3. Cluster means were computed for the 13 characters studied by Ward's minimum variance method and are presented in Table 4. Out of all clusters, cluster III showed higher mean values for most of the yield contributing traits like plant height, umbel diameter, days to $50 \%$ flowering, umbel per plant indicating the importance of cluster genotypes in coriander yield improvement programmes. Crossing between the genotypes of two clusters appeared to be most promising to combine the desirable characters. In the present investigations, cluster IV was found more divergent and there will be more chances of getting better segregants in $\mathrm{F}_{2}$ and subsequent generations from the crossing genotypes from cluster III and IV. Earlier workers like Singh et al., (2005), Ravi et al., (2009), Beemet et al., (2011) and Srivastava et al., (2000). From the present investigation, it can be concluded that Nine genotypes viz., cluster IV that includes 9 coriander varieties, namely R-CO-75, Siku-LC, Bareilly Local, RL-13, RS, ALC, LS-800, Small CO and CO4. Lowest numbers of genotypes were present in Cluster III, that include only three coriander genotypes; Pant Haritma, KPL and PD-21. For the traits, where selection is not effective, genetic divergence can play an important role on further partitioning of variability. In the present investigation, the cluster III and cluster IV were found more divergent and there will be more chances of getting better segregants in $F_{2}$ generations from the crossing of genotypes from cluster III and cluster IV. While cluster means, the cluster mean in case of days to $50 \%$ flowering was highest in cluster $\mathrm{V}$ and lowest in cluster III. While for days to first umbel unfolding was highest in cluster II and lowest in cluster I, for number of days to maturity duration was highest in cluster III and lowest in case of cluster IV. 
Table.1 Clustering pattern of twenty four genotypes of coriander on the basis of genetic divergence

\begin{tabular}{|l|c|l|}
\hline Clusters & Number of genotypes & Genotypes along with their sources \\
\hline I & $\mathbf{4}$ & Pant LC, PLI-100, PLC and Dhulet Local \\
\hline II & $\mathbf{4}$ & HL-Thick, HL-Normal, , HL-Big and TLC \\
\hline III & $\mathbf{3}$ & Pant Haritma, PD-21 and KPL \\
\hline IV & $\mathbf{9}$ & $\begin{array}{l}\text { R-CO-75, Bareilly Local, RL-13, RS, ALC, Siku-LC, Small CO, LS-800 } \\
\text { and CO-4 }\end{array}$ \\
\hline V & $\mathbf{4}$ & Kota, Hanumangarh Rajasthan, Jaunpur Local and Lakhimpur \\
\hline
\end{tabular}

Table.2 Average intra and inter cluster distance (D2)

\begin{tabular}{|l|l|l|l|l|l|}
\hline Clusters & I & II & III & IV & V \\
\hline I & $\mathbf{1 3 9 . 5 4}$ & & & & \\
\hline II & 308.24 & $\mathbf{3 1 . 7 8}$ & & & \\
\hline III & 556.77 & 1324.49 & $\mathbf{1 5 9 . 2 2}$ & & \\
\hline IV & 862.26 & 248.61 & 2271.66 & $\mathbf{9 9 . 6}$ & \\
\hline V & 692.21 & 216.09 & 1774.36 & 166.37 & $\mathbf{3 3 . 8 8}$ \\
\hline
\end{tabular}

Note: Diagonal values bold and underlined are intra-cluster distances. Off-diagonal values are inter-cluster distances

Table.3 The nearest and the farthest cluster from each cluster using Ward's Minimum Variance method in twenty four genotypes of coriander (Coriandrum sativum L.)

\begin{tabular}{|l|c|c|}
\hline Clusters No. & Nearest cluster with $\mathbf{D}^{\mathbf{2}}$ values & Farthest cluster with $\mathbf{D}^{\mathbf{2}}$ values \\
\hline I & II $(308.24)$ & IV (862.26) \\
\hline II & I (139.54) & III (1324.49) \\
\hline III & I (556.77) & IV $(2271.66)$ \\
\hline IV & II $(248.61)$ & V $(166.37)$ \\
\hline V & IV $(166.37)$ & III $(1774.36)$ \\
\hline
\end{tabular}

Table.4 Cluster means for different trait in twenty four genotypes of coriander

\begin{tabular}{|c|l|c|c|c|c|c|}
\hline \multirow{2}{*}{ Sr. No. } & Traits & \multicolumn{5}{|c|}{ Cluster No. } \\
\cline { 3 - 6 } & & I & II & III & IV & V \\
\hline 1 & Days to 50 \% flowering & 43.82 & 47.72 & 42.57 & 45.47 & 48.96 \\
\hline 2 & Days to first umbel unfolding & 33.45 & 39.69 & 34.48 & 36.80 & 39.48 \\
\hline 3 & Maturity duration & 104.26 & 102.75 & 111.95 & 88.02 & 90.91 \\
\hline 4 & Plant height (cm) & 55.79 & 48.61 & 64.98 & 34.15 & 40.86 \\
\hline 5 & Primary branches & 2.02 & 2.12 & 3.13 & 2.27 & 3.45 \\
\hline 6 & Secondary branches & 4.34 & 4.36 & 5.88 & 4.59 & 7.52 \\
\hline 7 & Umbel per plant & 12.56 & 11.20 & 15.55 & 6.43 & 7.95 \\
\hline 8 & Umbellates per umbel & 4.11 & 3.61 & 4.88 & 3.65 & 3.83 \\
\hline 9 & Umbel diameter (mm) & 21.59 & 24.49 & 32.40 & 27.05 & 29.61 \\
\hline 10 & Fruits per umbel & 19.01 & 13.91 & 22.57 & 13.75 & 18.20 \\
\hline 11 & Fruits per umbellate & 4.05 & 4.28 & 4.44 & 3.49 & 4.21 \\
\hline 12 & Test weight (gm) & 15.79 & 10.65 & 20.56 & 3.08 & 4.87 \\
\hline 13 & Seed yield per plant (gm) & 4.08 & 1.67 & 7.36 & 0.31 & 0.71 \\
\hline 14 & Seed yield per plot (gm) & 151.85 & 63.13 & 281.33 & 11.55 & 27.21 \\
\hline
\end{tabular}

Note: Bold figures indicate minimum and maximum values in each character 
Fig.1 Dendrogram showing relationship of 24 genotypes in five clusters based on Euclideans2 Distance

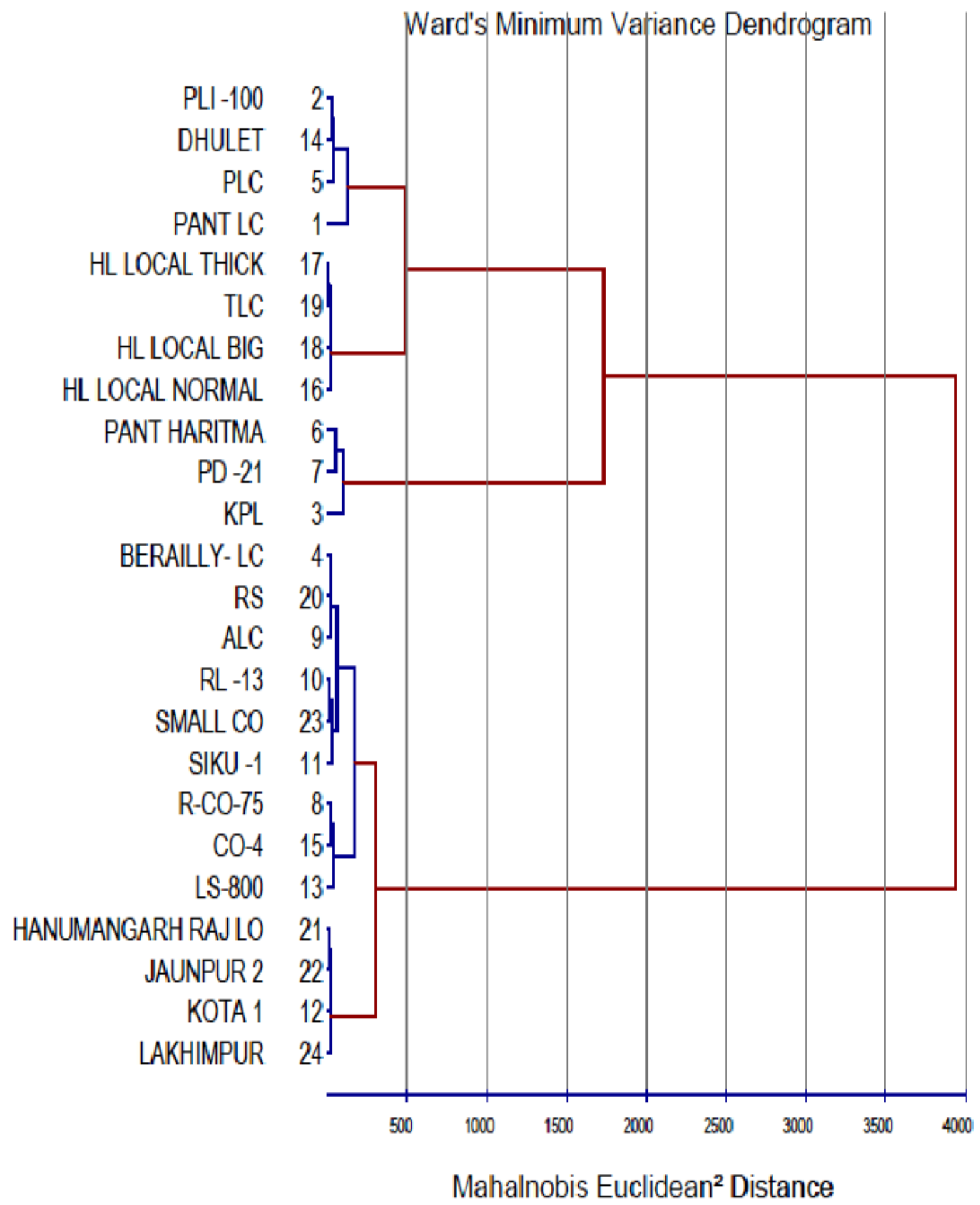


Fig.2 Intra and inter-cluster distance of 24 coriander (Coriandrum sativum L.) genotypes in five clusters based on Euclidean2 values

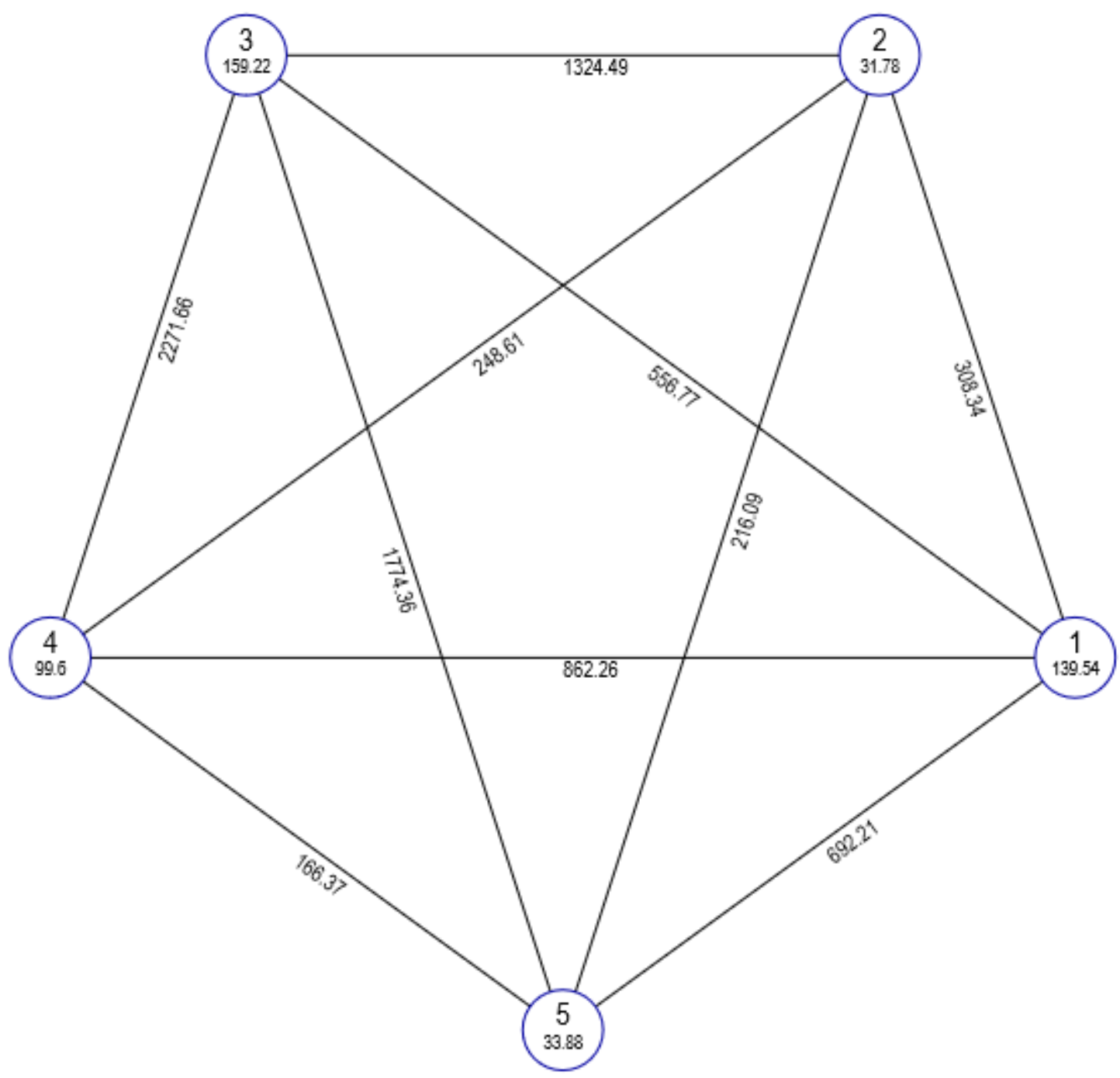

Euclidean ${ }^{2}$ Distance (Not to the Scale)

While cluster mean value for the plant height was found in cluster III and lowest in the cluster IV. The cluster means for number of primary branches per plant was highest in the cluster $\mathrm{V}$ and lowest in cluster I, while cluster mean for number of umbel per plant was highest in cluster III and lowest in cluster IV. For umbel diameter cluster mean was highest in case of cluster III and lowest in cluster I. The cluster mean for number of fruits per umbel was highest in cluster III and lowest in cluster IV. While cluster mean value for test weight was highest in the cluster III and lowest in cluster IV. For seed yield per plant cluster III has the highest values that means genotypes of this cluster must invariability be used for the improvement of yield while designing crossing plans as per their performance usually transferred to advance breeding generations if they are coming from additive gene effect. Therefore, hybridization between the genotypes of these groups can be 
effective for further improvement in Coriander.

\section{References}

Anderberg, M.R. 1993. Cluster Analysis for Application. Academic Press, New York

Beemnet M, Getinet A and Bizuayehu T. 2011. Genetic divergence in Ethiopian coriander accessions and its implication in breeding of desired plant type. African Crop Science Journal 19(1): 39-47.

Ravi R, Prakash M and Bhatt K. 2009. Aroma characterization of coriander (Coriandrum sativum L.) European
Food Research and Technology 225(34):367-374.

Singh S P, Katiyar R S, Rai S K, Tripathi S M and Srivastava J P. 2005. Genetic divergence and its implication in breeding of desired plant type in coriander (Coriandrum sativum L.). Journal of genetics 37(2):155-163.

Srivastava J P, Srivastava K and Tripathi S M. 2000. Path analysis in coriander (Coriandrum sativum L.). Spices and aromatic plants: challenges and opportunities in the new century Contributory papers Centennial conference on spices and aromatic plants, Calicut, Kerala, India, 20-23-23September. 2000 68-70.

\section{How to cite this article:}

Jaidev Chauhan, Suyanka Raturi, Ajaya Paliwal and Pankaj Bahuguna. 2019. Genetic Divergence and Cluster Analysis in Coriander Germplasm (Coriandrum sativum L.) in High Hills of Garhwal Himalayas. Int.J.Curr.Microbiol.App.Sci. 8(04): 1122-1127. doi: https://doi.org/10.20546/ijcmas.2019.804.129 